\title{
A luta de libertação em Guiné-Bissau e os estudantes da UNILAB
}

Beatriz Perote Fernandes Mônica Dias Martins

\begin{abstract}
RESUMO: As insurreições nacionalistas em África ganham força no período pós-segunda guerra. A insistência do regime colonial português em continuar explorando os territórios africanos fomentou a necessidade de adesão dos militantes bissau-guineenses à luta armada. Guiné-Bissau declara independência em 24 de setembro de 1973. Este percurso histórico e seus atores sociais ecoam ainda hoje nas trajetórias dos estudantes bissau-guineenses da UNILAB.
\end{abstract}

Palavras-chave: Guiné-Bissau. África. Nacionalismo. UNILAB

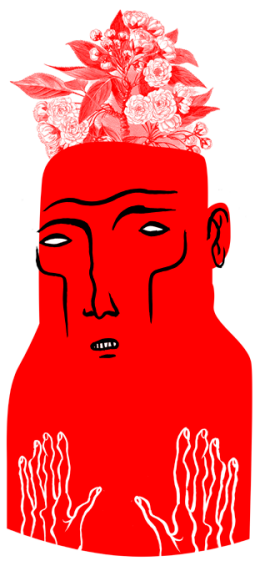

\section{The liberation struggle in Guinea-Bissau and the students of UNILAB}

\section{Beatriz Perote Fernandes}

Graduada em Ciências Sociais pela Universidade Estadual do Ceará e pesquisadora do Observatório das Nacionalidades. Educadora social na Pastoral do Menor. Email: beatrizperote@ gmail.com

\section{Mônica Dias Martins}

Professora da UECE, coordenadora do Observatório das nacionalidades e editora de Tensões Mundiais. Atualmente coordena o programa de pós-graduação em sociologia da UECE. Email:maricotam.martins@gmail.com

\begin{abstract}
Nationalist insurrections in Africa are gaining strength in the post-war period. The insistence of the Portuguese colonial regime to continue exploring African territories has fostered the need for Bissau-Guinean militants to join the armed struggle. Guinea-Bissau declares independence on September 24, 1973. This historical path and its social actors still echo today in the trajectories of the BissauGuinean students of UNILAB.
\end{abstract}

Keywords: Guinea Bissau. Africa. Nationalism. UNILAB

$$
\begin{array}{r}
\text { RECEBIDO: 05/03/2018 } \\
\text { APROVADO: 02/05/2018 }
\end{array}
$$




\section{INTRODUÇÃO}

A nação comporta debates mais profundos do que revelam à primeira vista suas manifestações multifacetadas. Com o olhar mais visceral, é possível perceber o percurso de um povo que passa a se identificar com um nome próprio, que utiliza uma linguagem específica, que nomeia certas pessoas como seus heróis, que percebe o lugar das práticas religiosas em sua história e que executa políticas que satisfaçam as necessidades da coletividade.

Em algumas experiências, as camadas populares participam, em certa fase, desse processo de autoidentificação ou de luta; em outras vivências, no entanto, apenas uma elite determina, oficialmente, o que compõe o imaginário coletivo. Assim, não é possível colocar manifestações dentro de uma mesma caixa e estabelecê-las como boas ou más. É essencial, portanto, compreender o processo histórico que perpassa um fenômeno que acontece em lugares diferentes, em tempos distintos, com demandas diferenciadas, mas que, em essência, pode carregar atributos universais.

Diante deste caráter singular e ao mesmo tempo universal dos processos de construção das nações, neste artigo expomos alguns conceitos que contribuem para relacionar o movimento de libertação nacional de Guiné-Bissau e sua repercussão nas lutas atuais dos estudantes bissau-guineenses da UNILAB. Para tanto foram realizadas entrevistas com alunos de graduação em Humanidades desta universidade e serão utilizadas mais a frente alguns trechos importantes para observar a ressignificação que a Luta de Libertação recebe destes novos estudantes bissau-guineenses. ${ }^{1}$

Benedict Anderson (2008) apresenta o nacionalismo como um "produto cultural específico". Para conhecê-lo profundamente, é preciso acessar suas raízes históricas e perceber como seus significados são transformados com o tempo.

Nesse sentido, para conhecer as motivações políticas desses estudantes da UNILAB, faz-se necessário recorrer à recente e histórica luta de libertação: no discurso destes alunos, estão presentes

1 Os cinco discentes entrevistados são identificados através das seguintes siglas: I.M.; S.C.; E.M.; A.M.; A.C. e em seguida informado que se trata de um estudante bissau-guineense. 
o partido que liderou o movimento anticolonial e Amílcar Cabral, considerado o pai da nacionalidade bissau-guineense.

O movimento nacional na então colônia portuguesa, assim como nos diferentes territórios do continente africano, brota após a Segunda Guerra Mundial, mas antes desse período já se manifestava através da agitação das elites e da adesão das massas à luta contra o nazismo e o fascismo. À semelhança de outras experiências, as expressões do nacionalismo em África desenvolvem-se em várias etapas, passando pelo entusiasmo de grupos da elite, envolvendo uma parcela maior da população no projeto de nação, chegando às lutas não violentas anticolonialistas e culminando, em alguns casos, na luta armada de libertação nacional (SILVÉRIO, 2013 p. 474).

Os termos que definem ou são relacionados ao processo histórico de libertação nacional em Guiné Bissau são a primeira questão. Miroslav Hroch, em entrevista à Daniel Esparza (2007), afirma não gostar do termo "nacionalismo", optando por utilizar a expressão "problemas nacionais" para compreender os processos de formação da nação. Assim, define nacionalismo de uma forma restrita, como a percepção de que os valores da nação são mais importantes que quaisquer outros princípios. É nesse ponto que há diversas confusões quanto às manifestações nacionais, pois, segundo o mesmo autor, este nacionalismo stricto sensu foi apenas uma dentre muitas formas de consciência que podem ter surgido dentro de um movimento nacional (HROCH, 2000, p.88).

Anderson observa que, na tentativa de conferir ao nacionalismo um caráter de ideologia, há uma tendência a se tratar de forma absoluta um conceito que, enquanto ato, é relativo, como é o caso do "Nacionalismo-com-N-maiúsculo" (ANDERSON, 2008, p.31-32). Indo de encontro à afirmação de Gellner: "o nacionalismo não é o despertar das nações para a autoconsciência: ele inventa nações onde elas não existem" (GELLNER, 1964, p.169 apud ANDERSON, 2008, p.32), Benedict indica que o crucial não está em julgar a veracidade ou a falsidade das nações pelo fato de serem imaginadas por movimentos nacionalistas, mas sim em perceber suas peculiaridades a partir do modo como são criadas. Logo, o termo nacionalismo surge como um conceito variante de movimento 
nacional porque ele também contribui, em certas experiências, para a construção de nações. É este percurso de formação, seja qual for a nomenclatura, que ajuda a perceber as singularidades das nações.

Eric Hobsbawm (1990, p.63, grifo do autor), no mesmo sentido de Anderson, acredita que imaginar a nação seja uma necessidade das pessoas para superar a ausência das "comunidades humanas reais", isto é, as comunidades tradicionais que entraram em declínio. Dessa forma, é a partir dos movimentos nacionais que se incitam outros sentimentos coletivos, nesse momento alcançando a esfera da macropolítica. A esta dinâmica ele dá o nome de "protonacionalismo", o qual se manifesta de duas maneiras: a primeira relativa às formas mais tradicionais de identificação popular e a segunda influenciada por questões políticas de grupos de elite ligados às Instituições do Estado, tendo acesso a mais meios para expandir suas ideias. Esta última aproxima-se da nação moderna, mas às duas, para alcançar o caráter de nacionalismo moderno, falta uma conexão direta com o esforço por uma unidade da organização política territorial (HOBSBAWM, 1990, p.63).

O termo protonacionalismo também é utilizado por Mário Pinto de Andrade ao se referir aos movimentos liderados por africanos letrados ${ }^{2}$, que inicialmente protestavam contra a ordem colonial que " [se] assentou num edifício ideológico cujas vertentes se compunham de uma legislação referente à assimilação dos autóctones (direitos civis e político ao nível dos indivíduos) e à integração dos territórios" (ANDRADE, 1997, p.25). Esses grupos foram caracterizados, pelo autor, como nativistas.

Essas primeiras iniciativas impulsionaram o nascimento do Protonacionalismo africano na ilha de São Tomé e Príncipe, que, na segunda metade do século XIX, tornava-se uma colônia de plantação para onde eram enviadas mãos-de-obra serviçais recrutadas em Angola, Moçambique e Cabo Verde (ANDRADE, 1997, p. 26). Entre os fatores teriam contribuído para a eclosão do Protonacionalismo no local, destaca-se a existência de nativos da ilha radicados em Portugal, formando uma elite composta

2 Que tinham domínio da língua do Império colonizador. 
por proprietários de terra e profissionais liberais que ansiavam por poder político (KAGIBANGA, 1997/1998, p.289). Este aspecto é comum a diversos movimentos nacionais, mostrando, portanto, que há certa regularidade em suas trajetórias.

Os movimentos nacionais nascem a partir de uma demanda própria de seu tempo e das necessidades de seu povo, por isso têm um caráter singular; mas, como se encontram dentro de um contexto internacional, podem carregar também algumas características em comum com manifestações de outras nações.

No artigo Do Movimento Nacional à Nação Plenamente Formada: O Processo de Construção Nacional na Europa, Miroslav utiliza o termo Movimento Nacional para definir "os esforços organizados de conquistar todos os atributos de uma nação plena" (HROCH, 2000, p.87-88).

Hroch pensa o movimento nacional, seja ele qual for, a partir de uma estrutura composta por três fases. Na chamada Fase A, os militantes dedicam-se a um estudo mais erudito sobre a cultura do grupo não dominante; na Fase B, o movimento busca conquistar mais adeptos através de uma movimentação patriótica a fim de despertar entre os novos integrantes a consciência nacional; na Fase $C$, uma parte significativa da população já se identifica com a identidade nacional idealizada e o grupo passa a ter um caráter de movimento de massa. Apenas nesta última fase poderia surgir uma estrutura social com os seus componentes anteriormente citados (HROCH, 2000, p.88-89, grifo nosso).

\section{A EXPERIÊNCIA BISSAU-GUINEENSE}

O que desencadeou a luta por independência ou que fez indivíduos de diversas etnias e classes a pensar em si próprios de forma coletiva, como uma nação não foi apenas o desejo dos intelectuais africanos, ao formarem em 1951 o Centro de Estudos Africanos. “Os intelectuais só podem 'inventar' comunidades nacionais se já existirem algumas precondições objetivas para a formação de uma nação" (HROCH, 2000, p.86). Isto é, estes estudantes já percebiam no povo africano a resistência à assimilação e é nele que se inspiram para iniciar um processo de luta anticolonial. 
A língua portuguesa exerce uma posição dentro da construção da nação bissau-guineense porque ela sempre foi negada, durante o regime colonial, a maior parte da sua população, mas esta mesma língua negada aos povos nativos foi utilizada para denunciar o imperialismo e para enaltecer a história dos povos africanos. Amílcar Cabral marca o lugar da língua do colonizador na experiência africana.

\begin{abstract}
Temos que ter um sentido real da nossa cultura. O português (língua) é uma das melhores coisas que os tugas nos deixaram, porque a língua não é prova de mais nada, senão um instrumento para os homens se relacionarem uns com os outros; é um instrumento, um meio para falar, para exprimir as realidades da vida e do mundo. [...]É a única coisa que podemos agradecer ao tuga, ao fato de ele nos ter deixado a sua língua, depois de ter roubado tanto da nossa terra (CABRAL,1976, p.101 apud PONSO, 2016, p.63-64).
\end{abstract}

A língua (e seus usos), dessa forma, é modificada pela cultura na qual está inserida. Um dos estudantes entrevistados, durante o trabalho de campo, chama atenção para a diversidade da Língua Portuguesa, afirmando que o Português falado na África é diferente do falado em Portugal e no Brasil.

Às vezes quando eu apresento o seminário em sala de aulas, o colega brasileiro diz assim: "Fala a minha língua!», Eu: "Qual é a sua língua? Esse aqui é o português que eu estou a falar". E ele:"Fala português brasileiro!", como é que eu falo português brasileiro? Como eu que não sei falar português brasileiro, eu falo português da Guiné, esse que eu aprendi que eu vou falar também. (A. C., estudante bissau-guineense).

As motivações do movimento nacional em Guiné-Bissau surgem a partir dos impulsos procedentes da experiência local que antecede os primeiros episódios de enfrentamento anticolonial. É necessário, assim, refletir o cenário colonial para entender o porquê dos movimentos nacionalistas nas colônias portuguesas nutrirem um caráter de luta armada, como afirma Mazrui e Wondji: 
Ademais, embora a conquista da independência nas outras colônias da África do oeste tenha, em seu conjunto, sido pacífica mediante a realização de mesas-redondas e debates entre partidos, no que tange à África portuguesa, por sua vez, ela foi longa, violenta e sangrenta, transformando-se em uma verdadeira guerra de libertação. A explicação das características que assim tomou a luta anticolonial na África portuguesa deve buscar as suas raízes nos princípios e nas práticas do colonialismo português, assim como na natureza dos movimentos nacionalistas (MAZRUI; WONDJI, 2010, p. 218-219).

O primeiro contato entre portugueses e os povos que habitam o atual território chamado de Guiné-Bissau aconteceu através do povoamento de Cabo Verde ${ }^{3}$, utilizado como depósito de seres humanos escravizados vindos da costa ocidental africana, em especial da Senegâmbia e de Guiné-Bissau.

Segundo Teixeira (2015), a população autóctone bissau-guineense, desde a chegada dos portugueses em 1446, sempre resistiu ao controle colonial. Algumas revoltas registradas oficialmente podem exemplificar a dificuldade do domínio português, como o motim que levou o governador da feitoria de Bissau, António José Torres, a solicitar cem homens de Cabo Verde que pudessem conter o grupo "rebelde".

A partir da Conferência de Berlim (1884-1885) acontece, de fato, a ocupação da África a partir da divisão do continente entre as potências europeias para sua exploração, não respeitando de nenhuma forma a territorialidade das etnias. Assim como o estabelecimento de fronteiras, a Conferência também trouxe consigo a escravatura como empecilho para o desenvolvimento do liberalismo nos territórios colonizados. Assim, o primeiro ato seria acabar com o comércio de mão-de-obra escrava entre os continentes. A Inglaterra (que havia abolido o tráfico em 1807) e a França posicionavam-se pela

3 Ao que tudo indica, não havia nenhuma população nas Ilhas que compõem Cabo Verde até a chegada dos portugueses. Tendo em vista sua localização estratégica no acesso aos três continentes (Europa, África e América), Cabo Verde tornou-se o centro do investimento colonial em detrimento de outras ex-colônias portuguesas em África. Assim, a sua ocupação deu-se a partir dos escravizados que chegavam da Senegâmbia e de Guiné-Bissau. (SILVÉRIO, 2013, p.480). 
extinção do tráfico de escravos, que dificultava o desenvolvimento de um novo modo de produção: o capitalista industrial.

Apesar do decreto de 10 de dezembro de 1836, elaborado por Sá da Bandeira, que abolia o tráfico negreiro em todos os territórios portugueses localizados abaixo da linha do equador, apenas em 1850, com a lei Eusébio de Queirós, o Brasil deixou de receber os navios negreiros. A mão-de-obra escrava da população negra ainda foi utilizada oficialmente, nas ex-colônias portuguesas em África, até 1869.

Silvério (2013) destaca que a escravidão é apenas um dos fatores que compõem a história da África e não deve ser associada apenas a este continente. Repercutir este tipo de ideia causa danos à trajetória de sua população, pois a África e os africanos possuem uma diversidade de conhecimentos ainda a revelar. Reproduzir essa única associação (África - escravidão) transforma as vítimas do passado e seus descendentes em autores do processo desumano que sofreram.

Que lugar deve ocupar o tráfico de escravos na história da África? Em outras palavras, que interesse o tráfico de escravos representa para nós, historiadores da África? Todas as raças foram escravas outrora. Mas todos os outros grupos populacionais encontraram um meio de eliminar essa noção de sua consciência histórica. Mas os africanos tanto superestimam a importância da escravidão em sua história que o termo "escravo" tornou-se quase equivalente a "africano". A escravidão é um fenômeno importante da ideologia do mundo ocidental moderno e devemos nos esforçar para entendê-lo. É esse fenômeno o principal responsável pela atitude negativa para com a África e os africanos (SILVÉRIO, 2013, p.177).

Assim, com o fim da escravidão, o regime colonial, para manter a agricultura, principal modo de produção de Guiné-Bissau, adotou outros modos de exploração do trabalho africano - o que Teixeira (2015) denomina como "escravatura doméstica". Isto possibilitou o envio de camponeses de Angola, Moçambique e Cabo Verde à ilha de São Tomé e Príncipe para garantir o rendimento da colônia de plantação (ANDRADE, 1997). 
Para justificar a utilização do trabalho serviçal de determinados grupos, o regime colonial define um modelo de "Homem colonizado" que vai repercutir nas diversas regulamentações do trabalho indígena. Seguindo a orientação de António Enes, foi promulgado o decreto de 1899. Enes era o responsável por pesquisar o trabalho dos nativos no fim do século XIX, e recomendava a necessidade do Estado obrigar a população autóctone a trabalhar para alcançar o estado de civilização. Em 1914, o decreto de 1899 foi substituído pelo Regulamento Geral do Trabalho Indígena nas Colônias Portuguesas, que buscava desenvolver também no nativo uma mentalidade moral e cívica para que estes pudessem contribuir, com o regime, na exploração mais profunda da terra. (ANDRADE, 1997).

Estes regimentos contribuíram para a categorização da população nativa, em especial nos territórios da Guiné-Bissau, Angola e Moçambique, classificando como civilizados aqueles que, através do trabalho, conseguiam sustentar-se e absorver a ideologia colonizadora; não-civilizados seriam os que resistiam tanto ao trabalho compulsório quanto à dominação territorial portuguesa.

Tendo em vista a dependência bissau-guineense de Cabo Verde até os últimos anos do séc. XIX ${ }^{4}$, a Igreja Católica, principal difusora do ensino oficial, estabeleceu suas principais atividades no arquipélago, contribuindo para a formação de capital humano que preenchesse a administração colonial em outros territórios portugueses em África. Apenas em 1957 foi estabelecido o primeiro Liceu Nacional em Guiné-Bissau, e, apesar do acesso ao ensino ser uma das principais ferramentas para a assimilação, apenas 1\% da população nativa tinha acesso à educação básica, destinada em especial aos europeus e a poucos descendentes de cabo-verdianos nascidos em solo guineense (TEIXEIRA, 2015).

Constata-se, assim, que era conveniente ao regime colonial, ao contrário do que se pregava, que não houvesse colonizados letrados - que não houvesse, enfim, africanos inseridos na sociedade portuguesa. Teixeira (2015) observa que o Estado colonial acreditava que os "indígenas" eram incapazes de aprender.

4 Guiné-Bissau deixou de ser dependente de Cabo Verde em 1897, recebendo o nome colonial de "Guiné Portuguesa" (TEIXEIRA, 2015, p.142). 
Com o fim da Segunda Guerra e a divulgação de ideias de descolonização, a estratégia para manter os domínios coloniais era atribuir certa autonomia administrativa e gerar desenvolvimento social e econômico nas colônias. Neste sentido, o governador Sarmento Rodrigues (1945-1948) procurou proibir castigos corporais no trabalho indígena e introduzir cabo-verdianos e guineenses mestiços na administração colonial. Este grupo representava uma elite intelectual que tivera acesso à educação colonial e ao ensino superior na Metrópole. Outra medida desse período foi a aprovação do Diploma dos Cidadãos, que substituía o Diploma dos Assimilados. Dessa forma, os nativos podiam passar do status de assimilados a europeus.

Na Guiné, a partir de 1946, passaram, portanto, a distinguir-se relativamente aos "indivíduos de raça negra, ou dela descendentes" apenas duas categorias - os indígenas e os cidadãos (ou "civilizados") -, abolindo aquela terceira categoria de "assimilado". Eram considerados indígenas ou indivíduos de raça negra ou dela descendentes que não preenchessem conjuntamente as seguintes quatro condições: a) falar, ler e escrever português; b) dispor de rendimentos suficientes ao sustento familiar; c) ter bom comportamento; d) ter cumprido os deveres militares. As condições de passagem à condição de cidadão português (ou seja, de "civilizado") eram enunciadas pelos artigos $2^{\circ}$ e $3^{\circ}$, sendo o bilhete de identidade o "único documento comprovativo da qualidade adquirida de não indígena" (artigo $4^{\circ}$ ) (SILVA, 2006, p.2, grifo do autor).

O governo português acreditava que a ameaça de descolonização partiria de agentes externos, contagiados pelas "revoltas" nas ex-colônias francesas que lhe faziam limite: Senegal e Guiné Conacri. Ao contrário, as primeiras mobilizações brotaram a partir de cabo-verdianos assimilados ou guineenses descendentes de cabo-verdianos que tiveram acesso à educação colonial e ao ensino superior na Metrópole.

Assim, dos poucos nativos assimilados - idealizados, pelo regime colonial, para serem "partidários do sistema, representando e mantendo intactos os interesses econômicos e administrativos do 
regime colonial nos países africanos como Guiné-Bissau, Angola e Moçambique" (TEIXEIRA, 2015, p.160) - surgiram os cidadãos portugueses na África, adeptos do regime colonial, como também aqueles "homens auto-investidos da missão de interpelar o poder dominante" (ANDRADE, 1997, p.21).

No início do século XX já surgia o grupo Liga Guineense (19101915) e, nos anos 1950, a Associação Desportiva e Recreativa dos Africanos. Ambos reivindicavam o acesso à cidadania dos "assimilados", sem levar em consideração as necessidades dos "indígenas" (TEIXEIRA, 2015). Estes agrupamentos não devem ser entendidos como movimentos de caráter nacionalista, porque não incluíam todas as categorias existentes no território; muito menos podem ser considerados descolonizadores, pois suas reivindicações almejavam a inclusão deste grupo na sociedade portuguesa.

Dessa maneira, nos anos 1950 acontece a "Fase A" do Nacionalismo em Guiné-Bissau. Acompanhando Hroch (2000), a primeira etapa das manifestações nacionalistas, neste território, surge a partir de intelectuais e seus estudos culturais sobre a sua terra (no caso, guineenses descendentes de caboverdianos). A importância desses estudos para a formação política dos futuros líderes africanos é confirmada na citação a seguir da autora Inocência Mata (2015, p.11):

Ora, esta fase foi claramente marcada por um activismo cultural, acirrados que estavam os antagonismos ideológicos com o poder colonial, com repercussões políticas consubstanciadas no aparecimento de formações políticas que se erigiriam a vanguardas nacionalistas nas colónias portuguesas - o PAI (depois PAIGC), a UPA, O MPLA e a FRELIMO - e que iriam conduzir as guerras de guerrilha a partir de 1961, a maior parte das quais (à excepção da UPA) integraria em 1958 o projecto colectivo do Movimento Anti-Colonialista (MAC), que congregava nacionalistas de Angola, Moçambique, Guiné, Cabo Verde e São Tomé e Príncipe, antecâmara do que viria a ser a Conferência das Organizações Nacionalistas das Colónias Portuguesas (CONCP), fundada em Abril de 1961 em Rabat, Marrocos, impulsionada por Amílcar Cabral e Aquino de Bragança. 
Assim, os estudantes das ex-colônias portuguesas que conseguiam bolsas de estudo na Europa, em especial os que viviam na Casa dos Estudantes do Império (CEI), iniciam o estudo da cultura dos povos colonizados da África e produzem uma literatura, de fato, africana a partir da criação do Centro de Estudos Africanos no seio da CEI. Criada pelo Estado Novo Português em 1944 para fortalecer a ideologia imperialista nos estudantes ultramarinos, esta instituição tornou-se, na verdade, o berço dos primeiros líderes do nacionalismo africano das ex-colônias portuguesas. Destacam-se, como figuras marcantes desse processo, Agostinho $\mathrm{Neto}^{5}$, Amílcar Cabral ${ }^{6}$ e Mário de Andrade. ${ }^{7}$

Surge a literatura africana, que se tornou a principal expressão daqueles estudantes contra o domínio colonial. Anteriormente, a produção literária era composta por textos de estrangeiros que viviam na Guiné-Bissau. Neste momento não há como pensar a literatura bissau-guineense de forma isolada. Na verdade, o ponto crucial deste ciclo é justamente a união de todos os estudantes ultramarinos para pensar a África em sua totalidade. Mesmo que ainda não houvesse um projeto de nação ou reivindicações políticas concretas, a primeira publicação do Caderno de Poesia Negra de Expressão Portuguesa8 ${ }^{8}$, em 1953, é fruto da união entre os africanos por uma só causa. No mesmo sentido:

5 António Agostinho Neto nasceu em 1922, em Kaxicane - Angola. Foi médico, poeta e político.Durante a luta anticolonial, tornou-se presidente do Movimento Popular de Libertação de Angola; após a independência, foi presidente do país entre 1975 e 1979.

6 Amílcar Lopes Cabral nasceu em 1924, em Bafatá -Guiné-Bissau. Foi engenheiro agrônomo e poeta. Considerado o Pai da Nacionalidade Caboverdiana e Bissau-guineense, foi um dos fundadores do PAIGC (Partido Africano para a Independência da Guiné e Cabo Verde). Meses antes da proclamação unilateral de independência da Guiné-Bissau, foi assassinado na República da Guiné (Guiné-Conacri).

7 Mário Pinto de Andrade nasceu em 1928, em Golungo Alto - Angola. Ensaísta, foi um dos fundadores da Liga Nacional Africana e o primeiro presidente do Movimento Popular de Libertação de Angola. Antes mesmo da independência do país, liderou um grupo de intelectuais que se opunham à liderança de Agostinho Neto no MPLA.

8 Organizado por Francisco José Tenreiro, geógrafo e poeta são-tomense, e Mário Pinto de Andrade, ensaísta, poeta e político angolano. 
Assim, quando se fala em literatura, é inevitável falar-se do ideológico e do cultural, sobretudo em África onde as literaturas nasceram, historicamente, de uma conflitualidade, para protestar contra uma situação que era uma situação de conflito entre duas culturas, a portuguesa e a outra (MATA, 2014, p.108).

Outro importante poeta da literatura guineense de expressão portuguesa, com seu caráter combativo e denunciador da exploração colonial, é Vasco Cabral. No poema África! Ergue-te e caminha!, Cabral traz vários elementos que compõem o cenário colonial e invoca a África como uma unidade e na figura de "mãe" para lutar contra a opressão vivida, como no trecho:

“Desperta-me Mãe-África!

E serás mais minha mãe.

Desperta irmão negro!

E serás mais meu irmão

porque encontramos o caminho da vitória final!

Mãe África!

Vexada

Pisada

Calcada até às lágrimas!

Confia e luta,

E um dia a África será nossa!" 9

Mas estes intelectuais africanos, estudantes ultramarinos das províncias portuguesas, começaram a sentir a necessidade do retorno à terra para que estes anseios pudessem criar forma. Até então, suas produções funcionavam como uma denúncia internacional, atingiam um público letrado, mostravam a outras nações a brutalidade do regime colonial português; mas era necessário ultrapassar esses limites para alcançar os povos nativos. Assim, o desejo de regresso ao solo africano ficava cada vez mais forte, como demonstra Alda Lara, médica e poetisa angolana, no poema Presença Africana:

9 Disponível em:<http://triplov.com/guinea_bissau/vasco_cabral/poemas/ index.htm>. Acesso em: 27 nov. 2017. 


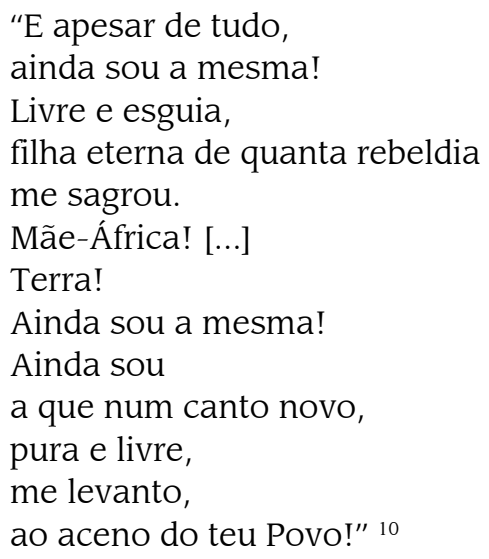

Em 1955, fontes do governo colonial em Guiné-Bissau informavam que um grupo de assimilados havia criado um Movimento para Independência Nacional da Guiné (MING) e estaria encorajando a adesão de outros nativos. Assim como informa Cunha:

O seu esforço de aliciamento às camadas médias da população mestiça e nativa - os "trabalhadores intelectuais" - e, simultaneamente, visa[vam] o despertar de uma consciência proletária em determinadas camadas menos evoluídas, dos centros urbanos, procurando a adesão dos trabalhadores braçais. (CUNHA, 1968, p.135 apud SILVA, 2006, p. 7).

O PAIGC (Partido Africano de Independência da Guiné e Cabo Verde), formado em 1956 por Amílcar Cabral e mais cinco companheiros, contemplando demandas das duas colônias, teve início com manifestações pacíficas, mas a partir de 1959 adotou outros meios. A Fase B, caracterizada pela agitação nacional e pela procura por novos adeptos, em Guiné-Bissau encontra um desafio maior. Os primeiros militantes, além de mobilizar a população do território, procuravam legitimar a sua causa no cenário internacional, como demonstra a publicação do Manifesto do MAC (MOVIMENTO..., 1960), em 1957, onde se pode perceber que os

10 Disponível em: <https://www.ueangola.com/bio-quem/item/741-aldaferreira-pires-barreto-lara-e-albuquerque>. Acesso em: 27 nov. 2017. 
movimentos de libertação das colônias portuguesas apoiavam-se também em mecanismos internacionais para o reconhecimento das suas nações.

A Conferência de Bandung ${ }^{11}$ condenou o colonialismo sob todas as formas e considerou-o como "um mal que deve ser rapidamente liquidado"; proclamou que "a sujeição dos povos ao jugo, à dominação e à exploração estrangeiras constitui uma negação dos Direitos Fundamentais do Homem, é contrário à Carta das Nações Unidas e é um impedimento à promoção da paz e da cooperação mundiais" (MOVIMENTO ANTICOLONIALISTA, 1957, p. 3).

O Massacre de Pindjiguiti, em agosto de 1959, tornou-se o marco da transição de um movimento de resistência para uma posição de confronto com o regime colonialista. A partir do assassinato, no cais de Pidjiguiti, de cerca de 50 trabalhadores que faziam uma greve por conta das más condições de trabalho, o movimento nacionalista em Guiné-Bissau percebe que não conseguiria expulsar o governo colonialista por uma via pacífica.

Teixeira (2015) observa que Amílcar Cabral considerava a luta armada como um ato de violência, mas que, devido às circunstâncias de repressão por parte do regime colonial, foi necessário utilizar um meio também violento.

O que importa é determinar quais as formas de violência que devem ser utilizadas pelas forças de libertação nacional, para não só responderem à violência do imperialismo mas também para garantirem, através da luta, a vitória final da sua causa, isto é, a verdadeira independência nacional (CABRAL, 1978, p. 85).

A partir de 1978, o PAIGC monta uma base de guerrilha no país vizinho, Guiné-Conacri, apoiado pelo antigo Bloco Soviético tanto para formação dos militantes do partido como para o

11 A Conferência de Bandung reuniu, na Indonésia, em 1955, os países afroasiáticos para planejar futuros acordos de cooperação entre essas nações. Não houve uma forte participação de países africanos porque muitos ainda estavam em situação colonial. 
abastecimento de equipamento militar, utilizando como principal tática a guerrilha e podendo, dessa forma, incluir os civis nesse processo (TEIXEIRA, 2015).

Assim, um princípio estabelecido pelo Partido para alcançar a independência através da luta era conhecer a realidade da terra: geográfica, econômica, social, cultural e política. E esta realidade não deveria partir, segundo Amílcar, da "cabeça do homem", mas ao contrário, esta deve impulsionar o homem a transformá-la. Nesse sentido, Cabral critica o personalismo dentro das organizações.

Eu posso ter a minha opinião sobre vários assuntos, posso ter a minha opinião sobre a forma de organizar a luta, de organizar um Partido, opinião que aprendi, por exemplo, na Europa, na Ásia, até mesmo talvez noutros países de África, nos livros, em documentos que li, com alguém que me influenciou. Mas eu não posso pretender organizar um Partido, organizar uma luta de acordo com aquilo que tenho na cabeça. Tem que ser de acordo com a realidade concreta da terra (CABRAL, 1978, p. 22).

Outro princípio estabelecido pelo partido que estava à frente na luta de libertação foi o de unidade ${ }^{12}$ fundamentada na diversidade dos sujeitos que a compõem. O movimento nacionalista em Guiné-Bissau passava por este outro desafio. Era necessário construir uma unidade africana, como afirma Cabral (1978, p.25):

Mas nós podemos lutar em todas as colônias portuguesas e até ganhar a nossa independência, mas se o racismo continuar na África do Sul, com os colonialistas a mandar ainda, direta ou indiretamente, em muitas terras de África, não podemos acreditar numa independência a sério em África.

Os grupos étnicos que compõem Guiné-Bissau foram um dos desafios de unidade. Esses agrupamentos sociais apresentam, em sua matriz, organizações diferenciadas. As sociedades horizontais

12 Amílcar Cabral, em Unidade e Luta (1978), afirma que o termo "unidade", estabelecido por ele como princípio do PAIGC e da luta de libertação nacional, não está ligado ao sentido estático. Ao contrário, refere-se a algo dinâmico, que muda, que está em movimento - e, no caso do PAIGC, a uma unidade composta por uma pluralidade de elementos. 
não possuem uma hierarquia política e social: as questões de conflito são resolvidas em conselhos (CABRAL, 1978). As sociedades verticais, como os fulas e manjacos, por sua vez, têm uma expressiva estratificação sócio-política na qual os papéis sociais são fundamentais para a composição da vida coletiva (TEIXEIRA, 2015).

Dessa forma, segundo Amílcar Cabral, algumas etnias, em detrimento de outras, estariam mais propensas a contribuir na luta de libertação. Isso aconteceria porque a organização social horizontal possibilita que os indivíduos que nela nascem e vivem sintam estranhamento, e mesmo revolta, diante de situações opressoras. Assim, ele explica que o número significativo de balantas inseridos no PAIGC ou que aderiam à luta não se dá porque esta etnia é melhor, mas porque a estrutura social vivida por esses grupos pode facilitar ou não a prática de regimes opressores como o colonial.

Nesta sociedade do mato, grande número de balantas pegou na luta e não é por acaso, não é porque os balantas são melhores que os outros. É por causa do tipo de sociedade que eles têm, sociedade horizontal (rasa), mas de homens livres, que querem ser livres, que não têm nenhuma opressão em cima, a não ser a opressão dos tugas [...] Enquanto que entre fulas e manjacos não é assim. A grande massa que sofre de facto é a de baixo, os trabalhadores da terra (camponeses). Mas entre eles e os tugas há muita gente. Já se habituou a sofrer, a sofrer com a sua própria gente, sob a opressão da sua própria gente (CABRAL, 1978, p.14).

O PAIGC, especialmente Cabral, apostava na instrução política da população bissau-guineense para conseguir alcançar a unidade entre todas essas etnias que compunham o contexto sócio-político e econômico de Guiné-Bissau. Este aspecto não era deixado de lado nem mesmo quando os territórios no campo eram conquistados. Paulo Freire, no livro Cartas a Guiné-Bissau, fala da dupla missão da educação nas Zonas Libertadas: "Uma educação que, expressando, de um lado, o clima de solidariedade que a luta provocava, de outro, o estimulava e que, encarnando o presente dramático da guerra, buscava o reencontro com o autêntico passado do povo e se dava a seu futuro" (FREIRE, 1978, p. 17). 
Mazrui e Wondji (2010, p. 221) afirmam que "o PAIGC implantou uma verdadeira democracia nas zonas libertadas" e continuam:

Assim que eles haviam liberado uma zona, eles ali aplicavam a sua política de libertação. Por um lado, eles expulsavam todos os funcionários e comerciantes coloniais, aboliam todos os impostos e direitos coloniais e punham termo ao trabalho forçado e às plantações obrigatórias. Por outro lado, e aqui é notório residir o aspecto mais positivo, eles instauraram um novo sistema comercial e criaram escolas e postos de saúde na mata lá onde antes jamais houvera, dotando-os de pessoal de formação e intervenção em saúde recrutado em meio a homens e mulheres muito amiúde formados na Europa ou em Cuba (MAZRUI ; WONDJI, 2010, p. 221).

Assim, posso chegar a um ponto importante que me encantou muito na Luta de Libertação Nacional em Guiné-Bissau. Tratase da inclusão de mulheres tanto em cargos políticos quanto no combate de guerrilha. Amílcar Cabral (1978, p. 68) afirmava que a participação de mulheres na luta foi tão importante quanto a dos homens, e apostava na formação das mulheres como alternativa para o casamento compulsório de meninas adolescentes: "[...] nós queremos fazer a promoção, o avanço das nossas mulheres e o melhor avanço, um dos principais avanços, é ensinar-lhes a ler e a escrever como deve ser."

O fato é que, mesmo com muita resistência de alguns homens, as mulheres estiveram inseridas no processo de libertação nacional e alcançaram espaços de destaque no cenário político guineense. Cito como exemplo Carmem Pereira, que exerceu, entre outras funções, a de comissária política em 1961, e em 1980 tornou-se presidente da Assembleia Nacional Popular.

[...] histórias de mulheres responsáveis políticas como Carmem Pereira ou Teodora Inácia Gomes, ou de comandantes militares como Titina Sila, ou de governantes de largas regiões como Francisca Pereira, histórias de mulheres como Tenem Camara, membro de um dos Tribunais Populares instituídos nas áreas libertadas, nos anos 60 do século XX (GOMES, 2016, p. 126). 
Através das características das fases de idealização e mobilização do movimento nacionalista de Guiné-Bissau são observados os esforços dos estudantes bissau-guineenses da UNILAB em ressignificar a nacionalidade guineense, através também de debates, da produção artística e científica, e no direcionamento profissional.

\section{FILHOS DA MAMA GUINÉ ONTEM E HOJE}

Hroch (2000) afirma que, mesmo quando suprimido na Fase A, o movimento nacional deixa meios para que possa ressurgir mais à frente. Um desses meios é a lembrança. Como informa no trecho a seguir: "A 'lembrança' da independência ou da condição de Estado anteriores, ainda que situadas em passado distante, pôde desempenhar um papel importante no estímulo à consciência histórica nacional e à solidariedade étnica." (HROCH, 2000, p.91).

Este artigo não busca quantificar a adesão de estudantes guineenses a cada posicionamento ou qualificar se suas posições sobre a Luta de Libertação Nacional são boas ou ruins, mas sim perceber a sua diversidade. Procuramos notar, durante a observação participante, os temas que mais incitavam discussões para aprofundá-los durante as entrevistas. Um deles é a questão étnica e como acontece sua conciliação com a nacionalidade.

Como o Seminário de Sociologia Africana sobre o Acordo de Conacri e Eleições em Guiné-Bissau, que ocorreu dia 23 de junho de 2017, buscava, fundamentalmente, criar um espaço de debate entre os alunos guineenses sobre o assunto proposto, tratamos este evento como principal base para construir hipóteses e preparar as entrevistas. Assim, observamos os seguintes pontos: a luta de libertação nacional de Guiné-Bissau como o marco para se pensar a situação política hoje no país; a tensão existente entre nacionalidade e etnia como influenciadora das posições políticas; o papel fundamental da UNILAB na construção do pensamento político dos estudantes.

O país conquistou a independência em 1973, pouco tempo depois do assassinato de Amílcar Cabral. A partir de 1980, no entanto, iniciaram-se vários golpes de Estado - o último aconteceu em abril 2012, no segundo turno das eleições. Não há como 
obter uma influência isolada da luta de libertação, pois o mesmo partido que liderou a emancipação de Guiné-Bissau comandou vários golpes de Estado desde 1980.

Percebemos que, ao falar de movimento nacional, é muito mais confortável lembrar a figura de Amílcar Cabral que a do PAIGC. Se o colonialismo foi o fator determinante para dar início ao movimento nacional em Guiné-Bissau, o período marcado por eleições diretas e governos democraticamente eleitos derrubados por golpes militares é o que impulsiona, da primeira fase, um novo pensamento nacional desta geração de estudantes da UNILAB. Isso pode ser sentido na seguinte fala:

Se pegarmos desde o primeiro golpe de Estado nos anos 1980, quem deu o golpe foi Nino Vieira, Nino Vieira era um combatente, era combatente de libertação. Depois disso, golpe de Estado com 07 de junho que era liderado por Assumane Mané, também era combatente. Parece que todos os golpes, todas essas pessoas aí passaram na luta de libertação. (S.C., estudante bissau-guineense).

Os movimentos nacionais na Europa do século XIX são analisados por Hroch (2000, p. 95) como produto de "uma crise de legitimidade, ligada a tensões sociais, morais e culturais" tendo como atores sociais, a princípio, os seus intelectuais. Olhando para o nacionalismo guineense, com suas particularidades, posso observar dentro no ambiente formado pela UNILAB, onde, além da formação de profissionais, existe um forte debate sobre a situação política da África - particularmente da Guiné-Bissau, cujos estudantes produzem uma literatura engajada própria de seu tempo, mas também rememorando fatos históricos e produzindo ciência sobre sua terra com um novo olhar.

Um exemplo disso é o blog chamado Linguística (Línguas), Literatura e Sociedade da Guiné-Bissau, alimentado por estudantes bissau-guineenses para divulgar sua produção literária e acadêmica. Na explicação sobre o objetivo do site, informa o administrador: "Não compromete com as questões políticas partidárias, mas sim com a literatura e sociedade que é uma forma de contribuir na mudança de mentalidade e olhares sobre a nossa realidade" 
13. Esta afirmação reforça mais uma vez um aspecto dessa nova geração: o não-comprometimento com as posições partidárias, o que não pode ser confundido com o não-comprometimento com os interesses nacionais. Percebemos que optar por não levantar a bandeira de algum partido seria uma forma de entrar em diálogo com os outros posicionamentos, apaziguar os ânimos entre os estudantes e manter uma discussão fundamentada nas necessidades do povo guineense.

Outro aspecto importante nesta pesquisa foi a auto-identificação dentro e fora dos limites territoriais de Guiné-Bissau, isto é, quais as coletividades incorporadas por estes estudantes. Durante o período colonial, como já foi falado, o povo era categorizado entre cidadão português e indígena. Lutar por um país livre era também resistir a uma identificação externa.

Assim, o propósito do movimento nacional, além de expulsar os colonialistas, era mobilizar as camadas populares e "despertar entre eles a consciência nacional" (HROCH, 2000, p. 88). Isto era uma tarefa árdua não só em Guiné-Bissau como também em muitos territórios do continente africano, porque nestes já havia agrupamentos anteriores ao pensamento nacional. Mesmo com a divisão colonial interferindo no uso da terra pelas etnias, estas ainda resistiram.

Na literatura acadêmica a etnia ainda é um fator atuante no cenário político africano, mas sentimos necessidade de ouvir dos próprios estudantes o quanto os grupos étnicos poderiam estar presentes nas suas discussões. Isso foi possível com a observação participante no Seminário de Sociologia Africana, no qual se debatia sobre as eleições de Guiné-Bissau e o Acordo de Conacri.

O estudante que compunha a mesa de debate iniciou sua fala observando que a crise política em Guiné-Bissau havia polarizado o cenário público no país e, a partir disso, as opiniões eram encaradas como posicionamentos "por encomenda", isto é, em nome de partidos políticos ou grupos étnicos. Baseadas nesta fala como em outras que a sustentavam, decidimos incluir este tema na pergunta sobre auto-identificação.

13 Disponível em: <https://literaturaesociedadeguineese.blogspot.com/>. Acesso em: 27 nov. 2017. 
As respostas foram variadas, e mesmo quando não respondidas totalmente deixavam rastros para indagações posteriores ou mesmo para perceber a tensão existente entre etnia e nacionalidade. Amílcar Cabral já previa esta associação problemática entre o sistema político e os grupos étnicos.

A maior asneira que se podia fazer na nossa terra seria criar na Guiné partidos ou movimentos na base de etnias, o que era um meio bastante bom, não só para o inimigo nos dividir ainda mais, durante a luta, mas também para garantir a sua vitória; a destruição da nossa independência, depois da luta, como os camaradas têm visto em alguns países africanos (CABRAL, 1978, p. 112).

Guiné-Bissau é uma nação na qual a pluralidade étnica é uma marca. Segundo Teixeira (2015), 99\% da população é negra e pertencente a grupos étnicos. A identificação étnica não impede a adoção da identidade nacional entre os estudantes bissau-guineenses, mas por seus discursos ela se mostra como um fator de divisão do sistema político, alcançando as relações entre os cidadãos. Isto ficou nítido no início das entrevistas. Enquanto quatro entrevistados falam de forma sintética sobre sua relação com a nacionalidade e o grupo tradicional, um dos estudantes preferiu não falar sobre etnia logo que iniciei o diálogo. Isso levou ao questionamento sobre a atuação desses grupos na conjuntura nacional.

Eu me identifico primeiramente como guineense e na segunda posição coloco a etnia, claro que a nação vem primeiro porque a gente tem uma nação com diferentes especificidades étnicas. [...] O meu grupo étnico faz parte da construção que eu sou hoje, e não posso esquecer disso tendo em conta toda a história, todas as resistências, porque as etnias que passaram pela colonização, a gente não pode esquecer da resistência para chegar até nossos rastros esse conhecimento até a nós (I.M., estudante bissau-guineense).

Sou guineense de Guiné-Bissau, tenho 28 anos, sou pertencente da etnia Balanta, mas primeiro identifico como guineense antes de identificar da etnia Balanta. (S.C., estudante bissau-guineense). 
Em termos de como é que eu me identifico, na verdade, na Guiné-Bissau eu me identifico sempre de Balanta, já na diáspora primeiramente eu me identifico como guineense ou africana e guineense da etnia Balanta. Aí se carrega primeiro o continente, depois a nacionalidade, aí vem a etnia. (E.M., estudante guineense).

Eu sou da etnia Manjaco, mas eu sou guineense. Eu sou também africana, considerada cidadã do mundo. (A.M., estudante bissau-guineense).

Sou da nacionalidade guineense, sou da GuinéBissau. (A.C., estudante bissau-guineense).

É notório que o conhecimento profundo sobre a Luta de Libertação Nacional se deu a partir do ingresso na Universidade da Integração, fruto da cooperação internacional entre os países que compõem a CPLP (Comunidades dos Países de Língua Portuguesa).

Nesta instituição, existe um diferencial no estudo sobre as sociedades africanas. O corpo docente é composto, além de pesquisadores brasileiros dedicados ao estudo da cultura afrodescendente, também por intelectuais do continente africano. Alguns desses professores também tiveram sua primeira formação superior no Brasil. Mungoi (2006) informa que, desde os anos 1990, as universidades brasileiras têm recebido um número significativo de estudantes do continente africano.

Assim, os estudantes estrangeiros da UNILAB conhecem sua história através do olhar dos seus compatriotas. No depoimento dos guineenses percebemos o quanto esta universidade tem sido importante para observar como os africanos são sujeitos e narram o seu percurso na história da humanidade.

Nós temos uma visão mais ampla, digamos, mais holística sobre a luta de libertação nacional aqui na UNILAB, a discussão sobre a África, a discussão sobre o colonialismo aqui na UNILAB. E aí você enxerga a importância de estudar na UNILAB, o privilégio que a UNILAB está dando para a gente. (I.M., estudante bissau-guineense). 
Quando a gente está em Guiné, a gente não tinha a oportunidade de conhecer a história própria da Guiné-Bissau, não se fala na escola, se fala só um pouco, pouquinho, bem pouco mesmo. A gente estuda da Grécia, Senegal, coisas vizinhas, mas pra falar da própria luta... da história própria do país, a gente não vê essa matéria dentro da sala de aula, vê pouca coisa. Quando a gente chegou aqui, a gente começou a estudar, da CPLP a gente conheceu um pouco, com a leitura a gente começou a identificar, a descobrir as coisas, mas quando a gente estava lá a gente não teve essa oportunidade de conhecer tanto a história da Guiné-Bissau como a gente tá vendo as coisas aqui. (A.M., estudante bissau-guineense).

A minha família, digamos assim, de um modo mais direto, nunca tive essa oportunidade de falar com isso. [...] Então isso, acerca da luta nacional, somente eu, em algures de Bissau que eu ouvia isso, uma certa discussão nas bancadas, nos corredores. Na escola, assim, não exatamente, mas na escola de formação dos professores, porque eu estudei em um Liceu que é chamado de ensino médio Samra Moisés Machel, que está próximo, frente a frente com... à direita com a Escola Superior Tchico-Té, que é uma escola de formação dos professores que atuam no ensino médio. Então diversas vezes eu ia pra lá pra fazer alguma pesquisa do ensino médio, então ouço nos corredores daquela escola acerca da luta de libertação nacional, mas realmente o que me levou ou o que me faz sentir essa luta de libertação nacional já é aqui na UNILAB, esse sentir essa realidade da luta de libertação nacional. (A.C., estudante bissau-guineense).

\section{CONCLUSÃO}

Os espaços de discussão não se limitam às salas de aula. Eles se tornam auto-organizativos, como é o exemplo da Associação dos Estudantes Guineenses na UNILAB. Ali, articulam-se ambientes de debate político e uma comunidade guineense é formada fora do território nacional. 
Amílcar Cabral, um sujeito atemporal e referência em todo o continente africano, tem sido novamente o mediador no processo de consciência nacional. Na fala dos entrevistados, assim como nas atividades promovidas por eles, este herói nacional é invocado para pensar a situação política hoje e fazer projeções.

Se o PAIGC foi perdendo credibilidade entre os guineenses desde o primeiro golpe com Nino Vieira, Amílcar, apesar da morte precoce, continua vivo. A UNILAB, tal como idealizada, representa a concretização do projeto de educação de Cabral e Paulo Freire, desenvolvido durante os primeiros anos de independência, que hoje é retomado com uma instituição que visa a cooperação internacional.

Se, para a geração de Cabral, o contexto colonial foi o que impulsionou as primeiras reações emancipatórias, quando jovens em situação mínima de privilégio, comparados à grande massa, construíram um projeto de nação onde todos teriam as mesmas oportunidades, hoje uma parte dos jovens estudantes guineenses migra não apenas para o norte, mas também para o sul do Atlântico, com o objetivo de construir relações, produzir conhecimento, questionar as intenções das parcerias e, a partir do acesso à ciência, repensar a política em seu país.

\section{REFERÊNCIAS}

ANDERSON, B. Comunidades imaginadas: reflexões sobre a origem e a difusão do nacionalismo. 4. ed. São Paulo: Companhia das Letras, 2008.

ANDRADE, M. P. de. Origens do nacionalismo africano: continuidade e ruptura nos movimentos unitários emergentes da luta contra dominação colonial portuguesa: 1911-1961. Lisboa: Publicações Dom Quixote, 1997.

CÁ, I. A.; DANFA, A. ; CABI, R. G. . Linguística (Línguas), Literatura e Sociedade da Guiné-Bissau. [S.l.: s.n.], 2016; (Blog). Dísponível em: $<$ https://literaturaesociedadeguineese.blogspot.com/>. Acesso em: 27 nov. 2017.

CABRAL, A. Unidade e luta. [S.l.: s.n.], [1978?]. Dísponível em: <http:// www.amilcarcabral.org/livro.pdf>. Acesso em: 20 dez. 2017. 
CABRAL, V. África! Ergue-te e caminha. In: FERREIRA, Manuel. Antologia poética da Guiné-Bissau. [S.l.: s.n.], 1990. Dísponível em: <http://www. triplov.com/guinea_bissau/vasco_cabral/poemas/index.htm>. Acesso em: 20 dez. 2017.

MANIFESTO do Movimento Anti-colonialista (MAC). 1960. Disponível em: <http://casacomum.org/cc/visualizador?pasta=04336.001.001\#!1>. Acesso em: 06 de set. 2017.

ESPARZA, D. Entrevista com Miroslav Hroch. Tensões Mundiais, Fortaleza, v. 3. n.4, p. 10 - 33, 2007.

FREIRE, P. Cartas à Guiné-Bissau: registros de uma experiência em processo. 2. ed. Rio de Janeiro: Paz e Terra, 1978.

GOMES, P. A. G. As outras vozes: percursos femininos, cultura política e processosemancipatóriosna Guiné-Bissau. Odeere: Revista do Programa de Pós-Graduação em Relações Étnicas e Contemporaneidade UESB, Jequié, ano 1, n. 1, jan./ jun. 2016. Disponível em: <http://periodicos. uesb.br/index.php/odeere/article/viewFile/5722/5524>. Acesso em: 30 set. 2017.

HOBSBAWM, E. J. Nações e nacionalismo desde 1780: programa, mito e realidade. Rio de Janeiro: Paz e Terra, 1990.

$\mathrm{HROCH}, \mathrm{M}$. Do movimento nacional à nação plenamente formada: o processo de construção nacional na Europa. In: BALAKRISHNAN, G. (Org.). Um mapa da questão nacional. Rio de Janeiro: Contraponto, 2000. p.85 -105 .

KAGIBANGA, V. A questão da Ruptura e da continuidade (proto)nacionalista na obra de Mário Pinto de Andrade: uma contribuição ao estudo sociológico do programa de pesquisa do $2^{\circ}$ volume da obra Origens do Nacionalismo Africano. África: Revista do Centro de Estudos Africanos, São Paulo, n. 20-21, p. 285-303, 1997/1998. Disponível em: <https://www.revistas. usp.br/africa/article/view/75259/78761 >. Acesso em: 18 out. 2017.

MATA, I. A casa dos estudantes do Império e o lugar da literatura na consciencialização política. Lisboa: UCCLA, 2015. Disponível em: $<\mathrm{http}$ ://www.uccla.pt/sites/default/files/a_casa_dos_estudantes.pdf>. Acesso em: 20 out. 2017.

O texto colonial: uma questão estético-ideológica. In: ŠPÁNKOVÁ, S. (Org.). (Des)colonização na literatura portuguesa contemporânea: breve antologia de textos literários e ensaísticos com atividades. Brno: Masarykovauniverzita, 2014. p. 108-113. Disponível em: <https://digilib. phil.muni.cz/data/handle/11222.digilib/130521/monography.pdf>. Acesso em: 14 set. 2017. 
MAZRUI, A. A. ; WONDJI, C. (Ed.). História geral da África, VIII: África desde 1935. Brasília: UNESCO, 2010. Disponível em: <http://unesdoc. unesco.org/images/0019/001902/190256por.pdf>. Acesso em: 04 jun. 2017.

PONSO, L. C.O estatuto do português e da línguas bantu moçambicanas antes, durante e depois da luta pela independência da nação em 1975. Revista Linguagem: Estudo e Pesquisa, Catalão, v.20, n.2, p. 57-86, jul./dez. 2016. Disponível: <https://www.revistas.ufg.br/lep/article/ viewFile/45815/22562>. Acesso: 05 set. 2017.

SILVA, A. E. D. Guiné-Bissau: a causa do nacionalismo e a fundação do PAIGC. Cadernos de Estudos Africanos, Lisboa, n. 9-10, p. 142-167, 2006. Disponível em: <http://journals.openedition.org/cea/1236\#quotation>. Acess o em: 30 set. 2016.

SILVÉRIO, V. R. (Coord.); ROCHA, M. C.; BLANCO RINCÓN, M.; BARBOSA, M. S. Síntese da Coleção História Geral da África: Pré-história ao século XVI. Brasília: UNESCO, 2013. Disponível em: <http://unesdoc.unesco.org/ images/0022/002270/227007POR.pdf>. Acesso em: 14 set. 2017.

TEIXEIRA, R. J. D. Cabo Verde e Guiné-Bissau: as relações entre a sociedade civil e o estado. Recife: Ed. UFPE, 2015. 